\title{
Performance of Lilium (Lilium elegans L.) Genotypes using Different Planting Media
}

\author{
Muhammad Zamin ${ }^{1 *}$, Fazli Rabbi², Shahen Shah ${ }^{3}$, Muhammad Amin ${ }^{4}$, Haroon Ur Rashid ${ }^{5}$, Hasnain \\ Alam ${ }^{6}$ and Sabahat Ali ${ }^{1}$
}

${ }^{1}$ University of Swabi, Khyber Pakbtunkhwa, Pakistan; ${ }^{2}$ University of Swat, Khyber Pakbtunkhwa, Pakistan; ${ }^{3}$ University of Agriculture, Peshawar, Khyber Pakhtunkhwa, Pakistan; ${ }^{4}$ Shaheed Benazir Bhotto University, Sharingal, Khyber Pakhtunkhwa, Pakistan; ${ }^{5}$ The University of Haripur, Khyber Pakbtunkbwa, Pakistan; ${ }^{6}$ International Islamic University, Islamabad, Pakistan.

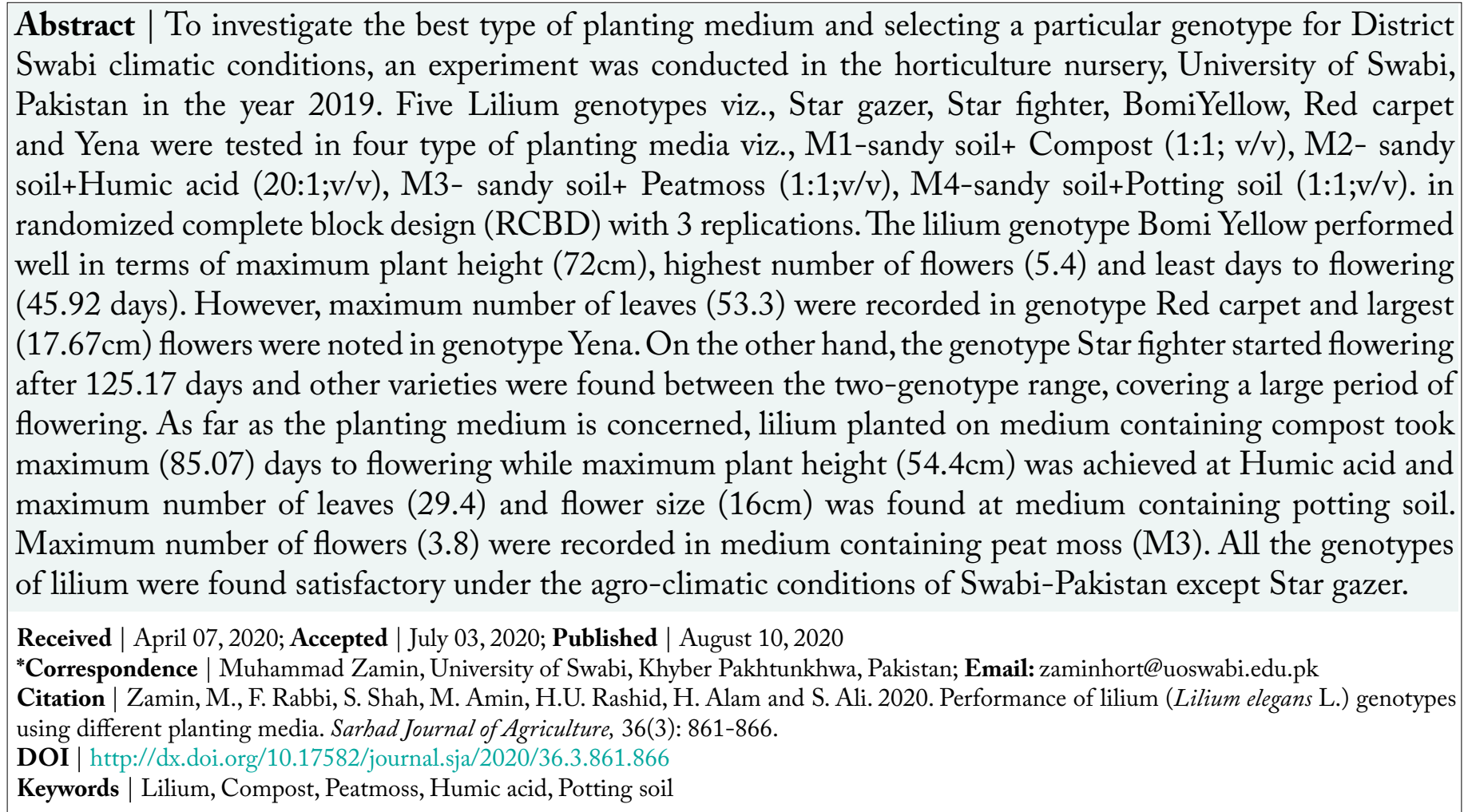

\section{Introduction}

L ilium is one of the most important genera of landscape plants used for cut flowers and pot or bed planting. The genus lilium belongs to the family liliaceae. Lilium is one of the most beautiful and popular ornamental bulbous plants. The appearance, beauty and color of the blooms are spectacular and very attractive (Rajera et al., 2017; Comber, 1949). In the language of flowers, the lilium is the symbol of purity and innocence.
Lilium deserves to be called the aristocrat of the plant world. The cultivated genotypes of genus Lilium are very popular in the floriculture market because of their diversity in colour, fragrance and suitability to many climatic conditions (Bahr and Compton, 2004). Lilium can be used for informal planting in landscaping or in combination with other flowers such as crocuses, bluebells and tulip to create flower meadows (Beck, 2010). These hybrids, particularly asiatic and oriental types are getting more attention in the cut flower 
industry as well as in landscaping (Lian et al., 2003). As far as their distribution is concerned, about 50-60 species are reported in Asia, 24 in North America and 12 in Europe. Lilies have been found to grow from sea level to an altitude up to 2000 metres, covering variety of soils such as alkaline, acidic and other types of soils. For quality cut flower production, however a good growing medium should be used. Lilies have non-tunicated tender bulbs and require porous, airy well drained growing medium with good quality of humus or organic matter. Characteristics of different materials used as substrates have the direct and indirect effects on plant growth and crop production. Therefore, standardization of a suitable growing medium for its cultivation is of utmost importance (Rajera et al., 2017). Although the agro-climatic condition of the Swabi seems to be favourable for this flower crop, however, it is not grown commercially for floriculture industry due to lack of information pertaining to its production and standard planting materials. In addition to other factors affecting lilium growth, yield and quality flowers, improved genotypes or hybrids play paramount role. So these genotypes are required to evaluate for their performance under local climatic conditions (Sharma et al., 2018). Therefore, proper genotypes screening in the local climatic context has become essential. Hence, present investigation was conducted to assess the performance of five genotypes of lilium under four planting media for their growth and flowering at Swabi.

\section{Materials and Methods}

The experiment was carried out during the year 2019 at the Ornamental Nursery of the Department of Agriculture, University of Swabi, Pakistan. Five Asiatic hybrid genotypes of Lilium elegans viz., Star gazer, Star fighter, Bomi Yellow, Red carpet and Yena were used in the experiment. Uniform sized bulbs were planted in pots having 1 gallon volume filled with four kinds of planting media in January 2019. Planting media used were comprised of M1-sandy soil+ Compost (1:1; v/v), M2- sandy soil+Humic acid (20:1; v/v), M3- sandy soil+ Peatmoss (1:1;v/v), M4sandy soil+Potting soil $(1: 1 ; \mathrm{v} / \mathrm{v})$. To prepare planting media, one container having 1 gallons capacity of sandy soil were mixed with one gallon container of respective organic amendments to get a mix of with $1: 1 ; \mathrm{v} / \mathrm{v}$. The mix was used for filling the pots for experiments. In case of M2, 19 gallons sandy soil was mixed with 1 gallon humic acid using 1 gallon container. Lilium genotypes were purchased in winter 2019 from retail nurseries in Islamabad and grown in a lath house of nursery. The experiment was laid out in completely randomized block design (factorial) with 3 replications. Each replication consisted of five plants. Before planting, bulbs were treated in solution comprising of Bavistin (0.1\%) and Dithane M-45 (0.2 $\%)$ for 30 minutes. Pots were placed under semi shade (30\% shade) conditions so that these plants can get similar environment and protect from unexpected and harsh weather conditions. All the cultural practices were followed and data were recorded time to time for five growth and floral parameters viz., Number of leaves, Days to flowering, plant height $(\mathrm{cm})$, Number of flowers and Flower size/dia $(\mathrm{cm})$.

Data was analyzed using analysis of variance (ANOVA) technique in Statistix software (version 8.1) and means were compared using LSD test at 5\% probability level (Steel et al., 1997).

\section{Results and Discussion}

\section{Number of days taken to flowering.}

As indicated in Table 1, different genotypes of lilium, growing media and their interaction had a significant effect on number of days taken to flowering. The highest (125.17) days to flowering were noted in Star fighter genotype followed by Star gazer taking 120.54 days to flowering while earlier flowering (45.92) was noted in Bomi Yellowge notype. As far as planting medium is concerned, M1 (Sandy soil+Compost; $1: 1 ; \mathrm{v} / \mathrm{v})$ prolonged the number of days taken from planting of bulbs till flowering taking 85.07 days while minimum (78.27) days were taken by lilium genotypes grown in M2 (Sandy soil+ Humic acid; $1: 1 ; \mathrm{v} / \mathrm{v})$. In case of interaction maximum (127.67) days were taken by Star fighter grown at M1 (Sandy soil+ Compost; $1: 1 ; \mathrm{v} / \mathrm{v})$. As indicated in interaction data, the earliest flowering (44.67 days) was noted in genotype Bomi Yellow when grown in M2 (Sandy soil+ Humic acid; 20:1; v/v). The early flowering of Bomi Yellow genotype is directly correlated with earliest colour bud formation in this medium. It can also be attributed to more vegetative growth attaining more plant height (Table 2) in the medium which contributed significantly to accumulation of photosynthates and in turn inducing optimum growth, early bud formation and flowering. Seyedi et al. (2012) who carried out experiment on effect of growing media on LA hybrid lilies concluded 
that cocopeat as medium amendment owing to its appropriate physical and chemical properties probably makes better growth of plants to decrease days from planting to reproductive stage. Findings of the present study are in close agreement with Dhiman (2003) who observed significant variation among Lilium hybrids with respect to days to visible bud formation. The variation in number of days required for first bud opening was primarily due to the different genetic mak-up of various genotypes and environmental conditions during the period of crop growth. Similar variation among the genotypes for days to first flowering was also reported by Sindhu et al. (2012) in Lilium.

Table 1: Effect of growing media on number of days taken to flowering of five lilium genotypes.

\begin{tabular}{lllllll} 
& \multicolumn{7}{c}{ Lilium genotypes } \\
Planting media & Yena & Red carpet & Star fighter & Star gazer & Bomi yellow & Means (medium) \\
M1 (Sandy soil+Compost; 1:1; v/v) & 65.00 & 64.33 & 127.67 & 121.67 & 46.67 & $85.07 \mathrm{a}$ \\
M2 (Sandy soil+ Humic acid; 20:1; v/v) & 61.67 & 44.67 & 122.33 & 118.00 & 44.67 & $78.27 \mathrm{c}$ \\
M3 (Sandy soil+ Peat moss; 1:1; v/v) & 64.67 & 64.33 & 125.33 & 119.83 & 45.33 & $83.90 \mathrm{~b}$ \\
M4 (Sandy soil+Potting soil; 1:1; v/v) & 66.33 & 60.00 & 125.33 & 122.67 & 47.00 & $84.27 \mathrm{~b}$ \\
Means (Genotypes) & $64.42 \mathrm{c}$ & $58.33 \mathrm{~d}$ & $125.17 \mathrm{a}$ & $120.54 \mathrm{~b}$ & $45.92 \mathrm{e}$ &
\end{tabular}

LSD (0.05) for: Genotypes 0.60; Planting medium 0.54; Planting medium x Genotypes 1.20

Table 2: Effect of growing media on plant height (cm) of five lilium genotypes.

\begin{tabular}{lllllll} 
& \multicolumn{5}{c}{ Lilium genotypes } \\
Planting Medium & Yena & Red carpet & Star fighter & Star gazer & Bomi yellow & Means (medium) \\
M1 (Sandy soil+Compost; 1:1; v/v) & 50.3 & 67.3 & 24.3 & 24.0 & 67.0 & $46.6 \mathrm{~b}$ \\
M2 (Sandy soil+ Humic acid; 20:1; v/v) & 52.7 & 58.0 & 44.3 & 33.0 & 84.0 & $54.4 \mathrm{a}$ \\
M3 (Sandy soil+ Peat moss; 1:1; v/v) & 51.0 & 64.3 & 45.3 & 37.0 & 62.0 & $51.9 \mathrm{ab}$ \\
M4 (Sandy soil+Potting soil; 1:1; v/v) & 54.3 & 42.7 & 35.0 & 38.3 & 75.0 & $49.1 \mathrm{ab}$ \\
Means (Genotypes) & $52.1 \mathrm{~b}$ & $58.1 \mathrm{~b}$ & $37.3 \mathrm{c}$ & $33.1 \mathrm{c}$ & $72.0 \mathrm{a}$ &
\end{tabular}

LSD ${ }_{(0.05)}$ for: Genotypes 6.43; Planting medium5.75; Planting medium x Genotypes12.85

\section{Plant height $(\mathrm{cm})$}

Plant height is significantly $(\mathrm{P} \leq 0.001)$ affected by genotypes, however, planting media has nonsignificant effect (Table 2). The tallest plants were produced by Bomi Yellow lilium $(72.00 \mathrm{~cm})$ followed by Red carpet lilium $(58.1 \mathrm{~cm})$ which was at par with Yena lilium while minimum was recorded in Star gazer producing $33.1 \mathrm{~cm}$ tall plants. The variations found in these lilium genotypes are in line with the findings of Sindhu et al. (2012). Similarly, Wilfret and Raulston (1971) also found similar trend of plant height during their evaluation trial on lilium genotypes. As far as different growing media is concerned, maximum plant height $(54.40 \mathrm{~cm})$ was observed in M2 (sandy soil + Humic acid; 20:1; v/v) followed by plant height attained at growing medium of M3 (Sandy soil+ Peat moss; $1: 1 ; \mathrm{v} / \mathrm{v})$ while lowest height of plants $(46.6 \mathrm{~cm})$ were found in plants grown in planting medium of M1 (sandy soil+ compost; $1: 1 ; \mathrm{v} / \mathrm{v}$ ). Data pertaining to interaction between genotypes and growing media shows that bulbs of Bomi Yellow lilium grown in M2 (sandy soil + Humic acid; 20:1; v/v) recorded maximum plant height $(84.00 \mathrm{~cm})$. The results of other interaction were also found significant. The variations among lilium genotypes might be due to the genetic makeup of each genotype. Although, lilium can be grown on any soil type, however, soil with more nutritive status gave better performance. Similar trend of increase in plant height due tonutrients rich media was also recorded by Singh (2013).

\section{Number of leaves per plant}

Different genotypes of lilium performed differently $(\mathrm{P} \leq 0.001)$ as far as the number of leaves per plant is concerned whereby maximum (53.25) number of leaves per plant was found in genotype Red carpet followed by Bomi Yellow (34.33). On the other hand, the lowest (4.00) number of leaves were produced in genotype Star fighter which was at par with Star gazer. Similar variation in the vegetative parameters of lilium was also reported by earlier researchers (Pandey et al., 2008; Dwibedi et al., 2002; Deka et al., 2010). Difference in vegetative growth characters of different genotypes may be due to varied growth 
rate and their genetic make ups as a result, variation in phenotypic expression are expected to occur. The difference in various parameters among the genotypes may be due to different genetic makeup of genotypes (Barik, 2013). As far as number of leaves per plant, bulbs grown in M4 (Sandy soil+Potting soil; 1:1; $\mathrm{v} / \mathrm{v})$ resulted in maximum number of leaves per plant (29.10). On the other hand, minimum (21.80) leaves were produced in M2 (Sandy soil+ Humic acid; 1:1; v/v). Similar results were obtained in M1 and M2 as well (22.8 and 25.10 respectively).

Data pertaining to interaction between genotypes and growing media showed that maximum number of leaves per plant (72.67) was found in genotype red carpet were grown in M4 (Sandy soil+Potting soil; $1: 1 ; \mathrm{v} / \mathrm{v})$. In contrast, least number of leaves were produced when Star fighter (1.00) was grown in M1 (Sandy soil+Compost; 1:1; v/v) and M3 (Sandy soil+ Peat moss; $1: 1 ; \mathrm{v} / \mathrm{v})$. Lilium bulbs grown on M4 produced maximum number of leaves per plant irrespective of genotypes. It might be due to increased water holding capacity and enhanced nutrient uptake (Tomati et al., 1988). Increased number of leaves on media amended with vermicompost has also been reported by Moghadam et al. (2012) in lilium asiatic hybrid 'Navona'.

\section{Number of flowers per spike}

An appraisal of data in Table 4 revealed that lilium genotypes differ significantly from each other with respect to number of flowers per spike. More number of flowers per spike (5.4) was recorded in Bomi Yellow lilium followed by Star fighter (3.58) which was at par with Red carpet lilium (3.33). The least number of flowers were produced by Yena lilium and Star gazer producing 1.58 and 1.57 flowers respectively.

Table 3: Effect of growing media on number of leaves/plants of five lilium genotypes.

\section{Lilium genotypes}

$\begin{array}{lllllll}\text { Planting Medium } & \text { Yena } & \text { Red carpet } & \text { Star fighter } & \text { Star gazer } & \text { Bomi yellow } & \text { Means (medium) } \\ \text { M1 (Sandy soil+Compost; 1:1; v/v) } & 24.0 & 53.3 & 2.8 & 1.8 & 32.0 & 22.8 \mathrm{~b} \\ \text { M2 (Sandy soil+ Humic acid; 20:1; v/v) } & 22.7 & 42.3 & 1.0 & 9.0 & 34.0 & 21.8 \mathrm{~b} \\ \text { M3 (Sandy soil+ Peat moss; 1:1; v/v) } & 41.0 & 44.7 & 11.3 & 2.2 & 26.3 & 25.1 \mathrm{~b} \\ \text { M4 (Sandy soil+Potting soil; 1:1; v/v) } & 19.7 & 72.7 & 1.0 & 8.7 & 45.0 & 29.4 \mathrm{a} \\ \text { Means (Genotypes) } & 26.8 \mathrm{~b} & 53.3 \mathrm{a} & 4.0 \mathrm{~d} & 5.4 \mathrm{~d} & 34.3 \mathrm{c} & \end{array}$

LSD (0.05) for: Genotypes 3.78; Plantingmedium3.38; Planting medium x Genotypes7.56

Table 4: Effect of growing media on number of flowers/spike of five lilium genotypes.

\section{Lilium genotypes}

$\begin{array}{lllllll}\text { Planting Medium } & \text { Yena } & \text { Red carpet } & \text { Star fighter } & \text { Star gazer } & \text { Bomi yellow } & \text { Means (medium) } \\ \text { M1 (Sandy soil+Compost; 1:1; v/v) } & 2.0 & 2.7 & 2.3 & 1.2 & 4.7 & 2.6 \mathrm{c} \\ \text { M2 (Sandy soil+ Humic acid; 20:1; v/v) } & 1.0 & 3.3 & 4.3 & 4.0 & 6.0 & 3.7 \mathrm{a} \\ \text { M3 (Sandy soil+ Peat moss; 1:1; v/v) } & 2.3 & 3.7 & 4.7 & 2.2 & 6.0 & 3.8 \mathrm{a} \\ \text { M4 (Sandy soil+Potting soil; 1:1; v/v) } & 1.0 & 3.7 & 3.0 & 2.7 & 5.0 & 3.1 \mathrm{~b} \\ \text { Means (Genotypes) } & 1.6 \mathrm{~d} & 3.3 \mathrm{~b} & 3.6 \mathrm{~b} & 2.5 \mathrm{c} & 5.4 \mathrm{a} & \end{array}$

LSD ${ }_{(0.05)}$ for: Genotypes 0.39; Planting medium0.35; Planting medium x Genotypes0.78

Table 5: Effect of growing media on size of flower (cm) of lilium genotypes.

\begin{tabular}{lllllll} 
& \multicolumn{7}{c}{ Lilium genotypes } \\
Planting Medium & Yena & Red carpet & Star fighter & Star gazer & Bomi yellow & Means (medium) \\
M1 (Sandy soil+Compost; 1:1; v/v) & 16.7 & 15.3 & 15.7 & 11.2 & 15.0 & $14.8 \mathrm{~b}$ \\
M2 (Sandy soil+ Humic acid; 20:1; v/v) & 21.0 & 15.7 & 13.7 & 14.7 & 14.3 & $15.9 \mathrm{a}$ \\
M3 (Sandy soil+ Peat moss; 1:1; v/v) & 16.3 & 15.3 & 14.0 & 12.5 & 14.0 & $14.4 \mathrm{~b}$ \\
M4 (Sandy soil+Potting soil; 1:1; v/v) & 16.7 & 16.3 & 16.7 & 14.7 & 15.7 & $16.0 \mathrm{a}$ \\
Means (Genotypes) & $17.7 \mathrm{a}$ & $15.7 \mathrm{~b}$ & $15.0 \mathrm{c}$ & $13.3 \mathrm{~d}$ & $14.8 \mathrm{c}$ &
\end{tabular}

LSD (0.05) for: Genotypes 0.47; Planting medium0.42; Planting medium x Genotypes0.94 
Number of flowers per spike was significantly affected by different growing media also. Lilium bulbs grown in M3 (Sandy soil+ Peat moss; 1:1; v/v) gave the highest number (3.8) of flowers which was at par with M2 (Sandy soil+ Humic acid; 20:1; v/v) giving 3.7 flowers per spike. Interaction data was also significant. The largest number of flowers per spike (6.00) was recorded in Bomi Yellow lilium in two kinds of medium (M2 and M3. Minimum flowers were produced by Yena lilium at the media containing humic acid and potting soil (M2 and M4). Optimum growing conditions provided by the medium amended with Humic acid helped to optimise the plant health resulting in the production of a greater number of flowers/spike. Humic acid is a sustainable source of macro and micro nutrients and has a considerable potential for improving plant growth significantly when used as soil amendments in horticultural crops (Sahni et al., 2008). In a similar a study on asiatic hybrid lilium 'Navona', Moghadam et al. (2012) also reported a greater number of flowers per spike in amended medium.

\section{Size of flower $(\mathrm{cm})$}

As indicated in Table 5, genotypes, growing media and their interaction had a significant effect on flower size $(\mathrm{cm})$. The largest $(17.67 \mathrm{~cm})$ flowers were obtained by Yena followed by Red carpet producing $15.67 \mathrm{~cm}$ flower while smallest flower was found in Star gazer $(13.25 \mathrm{~cm})$. Among different growing media, the large sized flower $(16.00 \mathrm{~cm})$ was observed in M4 (Sandy soil+Potting soil; $1: 1 ; \mathrm{v} / \mathrm{v})$ which as at par with M2 (Sandy soil+ Humic acid; $1: 1 ; \mathrm{v} / \mathrm{v}$ ) providing $15.86 \mathrm{~cm}$ flowers. In contrast, smaller sized flower $(11.93 \mathrm{~cm})$ was found in lilium grown in M3 (Sandy soil+ Peat moss; $1: 1 ; \mathrm{v} / \mathrm{v})$. Interaction between cultivar and growing media shows that maximum flower size $(21.00 \mathrm{~cm})$ was obtained when bulbs Yena lilium were grown on M2 followed by media containing compost (M1) and potting soil (M4) producing flower sizes 16.67 for both. Larger flower size obtained in M2 in the present studies could be attributed to the corresponding larger bud size observed in this medium. It may be concluded that variation in diameter of flower mainly due to the genetic makeup which might have been further modified by the environmental condition prevailing during the time of experiment. These results are in line with the findings of Rajera et al. (2017).

\section{Conclusions and Recommendations}

Based on the results, it is concluded that most of the lilium genotypes performed well except Star gazer and have good potential for growth and adaptability to the local climatic conditions. Genotype Bomi Yellow was on the top while other three genotypes were found satisfactory. with appropriate planting media of potting soil and Peat moss.

\section{Novelty Statement}

Keeping in view the importance of Lilium in floriculture industry, adopting better production technology is a value addition for farmer's products.

\section{Author's Contribution}

$\mathrm{MZ}$ contributed in data processing and interpretation of results and organized over all manuscript development. FR contributed in analysis and discussion of results. SS contributed in review of literature. MA contributed in analysis and discussion of results. HUR helped in manuscript review and language correction. HA helped in introduction section and review of literature. SA helped in data collection and record.

\section{Conflict of interest}

The authors have declared no conflict of interest.

\section{References}

Bahr L.R. and M.E. Compton. 2004. Competence for in vitro bulb regeneration among eight Lilium genotypes. Hortic. Sci., 39(1): 127-129. https://doi.org/10.21273/HORTSCI.39.1.127

Barik, D., 2013. Comparative performance of Asiatic hybrid lily varieties under open and protected environment. M.Sc (Ag) thesis, submitted to Orissa Univ. Agric. Technol., Bhubaneswar.

Beck, C., 2010. Yorkshire moreish. Garden Illustrated, 5259.

Comber, H., 1949. A new classification of the genus Lilium. Lily year book, R. Hortic. Soc., London. 13: 86-105.

Deka, K.R., C. Bidyut and V.V. Patel. 2010. Evaluation of Asiatic Lilium under sub-tropical mid hills of Meghalaya. J. Ornam. Hortic., 13(4): 257-260.

Dhiman, M.R., 2003. Evaluation of hybrid lily under Kullu conditions. J. Ornam. Hortic., 6(2): 154-155.

Dwibedi, S.K., D.P. Attrey, P. Eli and A. Kareem. 
2002. Introduction and evaluation of Asiatic Lilium in cold arid conditions of Ladkh. Floriculture Research Trendin India. Proc. Nat. Symp. Indian Floric. Millennium, Lal-Bagh, Banglore, pp. 293-294.

Lian, M.L., D. Chakrabarty and K.Y. Paek. 2003. Growth of oriental hybrid 'Casablanca' bulblet using bioreactor culture. Sci. Hortic. 97: 41-48. https://doi.org/10.1016/S03044238(02)00086-9

Moghadam, A.R.L., Z.O. Ardebili and F. Saidi. 2012. Vermicompost induced changes in growth and development of Lilium Asiatic hybrid var. Navona. Afr. J. Agric. Res., 7(17): 2609-2621. https://doi.org/10.5897/AJAR11.1806

Pandey R.K., S. Dogra, J.P. Sharma and S. Jaiswal. 2008. Evaluation of Asiatic huybrid lily cultivars under subtropical condition of Jammu region. J. Plant Sci. Res., 24(2): 213-214.

Rajera, S., P. Sharma and B.K.P. Sharma. 2017. Effect of Different Growing Media on Growth and Flower Production of LA Hybrid Lily. Int. J. Curr. Microbiol. App. Sci., 6(8): 2076-2089. https://doi.org/10.20546/ijcmas.2017.608.247

Sahni, S., B.K. Sarma, D.P. Singh, H.B. Singh and K.P. Singh. 2008. Vermicompost enhances performance of plant growthpromoting rhizobacteria in Cicer arietinum rhizosphere against Sclerotium rolfsii and quality of strawberry (Fragaria $\mathrm{x}$ ananassa Duch.). Crop
Prot., 27: 369-376. https://doi.org/10.1016/j. cropro.2007.07.001

Seyedi, N., A.M. Torkashvand and M.S. Allabyari. 2012. The impact of perlite and cocopeat as the growth media on Lilium. Asian J. Exp. Biol. Sci., 3(3): 502-505.

Sharma, R., R. Kumar and D.S. Dahiya. 2018. Studies on the performance of lilium varieties under polyhouse. J. Pharm. Phytochem., 7(4): 2711-2713.

Sindhu S.S., J.P. Singh and R.K. Singh. 2012. Evaluation of Lilium cultivars under northern plains. Int. J. Agric. Sci., 8(2): 460-461.

Singh, J., 2013. Standardization of growing substrates and NPK doses for growth and flowering of alstroemeria (Alstroemeria bybrida L.) Ph.D. thesis submitted to Dr. Y.S. Parmar Univ. Hortic. For., Nauni, Solan, Himachal Pradesh.

Steel, R.G.D., J.H. Torrie and D.A. Dickey. 1997. Principles and procedures of statistics: A biometric approach. 3rd ed. Mc Graw Hill Book Co. Inc., New York.

Tomati, U., A. Grappelli and E. Galli. 1988. The hormone-like effect of earthworm casts on plant growth. Biol. Fert. Soils., 5: 288-294. https://doi.org/10.1007/BF00262133

Wilfret, G.J. and J.C. Raulston. 1971. Relation of corm position on gladiolus flower quality and yield. Hort. Sci., 6(3): 282-283. 